Um aspecto fundamental desse livro refere-se à análise que o autor faz da Revoluçẫo Científico-Técnjca (RCT), um tema recorrente desse autor e que ele o explora com mais profundidade em outras obras, principalmente em Revoluço Cientifífo-Técnica e Capitalismo Contemporâneo, de 1983, também editado pela Vozes. É em tomo das interaçoes entre a RCT e o processo de globalização da economia que o autor constról a sua argumentaçăo básica para analisar a posição da América Latina e Caribe diante das mudanças que estẫo ocorrendo no cenário internacional, bem como para propor caminhos alternativos para esta região, caminhos que passarão necessariamente por uma integração regional capaz de romper com o modo dependente e subalterno que tem caracterizado a sua inserção na economía mundial. Através da análise de projetos de integração, fracassados ou em curso, a exemplo da ALALC - Associação Latino-Americana de Livre Comércio e do Pacto Andino, o autor discute os limites e as dificuldades para se alcançar esse tipo de integração regional. Os últimos capítulos são dedicados a este assunto e constituem uma importante contribuiçăo para o debate que atualmente se faz em torno do MERCOSUL e do NAFTA - Acordo de Livre Comércio da América do Norte.

Mesmo sem fazer concessöes aos problemas que afetam a América Latina e o Caribe, o texto traz uma mensagem otimista, pois a crise de hegemonia no mundo contemporâneo, um aspecto importante da conjuntura internacional, favorece a negociaçăo $\mathrm{e}_{\text {, }}$ assim, essa regiâo passa a ter "uma oportuntdade unica para afirmar a sua unidade sem chocar-se abertamente com a hegemonia americana" (p. 139). Concluindo, trata-se de uma obra importante e que estava faltando, não só porque estabelece um confronto com as teses neoliberais muito em voga no momento, mas principalmente porque continua o debate sobre o desenvolvimento sustentável, que teve na Eco-92, em julho de 1992, no Rio de Janeiro, um form de discussões privilegiadas.

\section{THE JAPANESE POWER GAME: WHAT IT MEANS FOR AMERICA}

de WILLIAM J. HOLSTEIN

New York: Penguin Books, 1991, 351 p.

por Gilmar Masiero, Doutorando em Administração na EAESP/FGV.
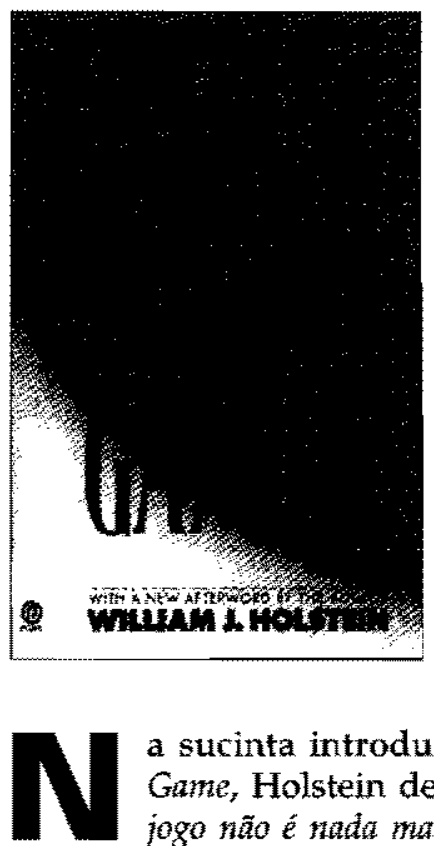

a sucinta introduçấo ao The Japanese Power Game, Holstein declara que ".. o que esta em jogo não é nada mais nada menos que a modelagem do século XXI. Agora que os japoneses passaram os soviéticos, Estados Unidos e Japão são as duas maiores ecorommias mundiais. Em toda a história, paramente duas socie dades com tâo diferenciados valores têm se permitido tornarem-se tão interdependentes. Embora as duas possuam áreas de genutna cooperação, elas estão também engajadas em sérias confrontaçöes. E mais que una disputa econômica. É uma questao de quais regras e quais valores iräo prevalecer. Então, como o jogo do poder é jogado internamente e como o Japão joga internacionalmente são importantes questões".

Essas questões são respondidas em 351 păginas do melhor jornalismo mundial, organizadas em um livro composto de 23 subtítulos distribuídos em quatro partes: A sociedade poderosa; Escândalo; Na direção do futuro; Resposta americana. No final do livro, encontram-se dois apêndices com resultados de pesquisas sobre o que os japoneses pensam dos Estados Unidos e o que os americanos pensam da Empresa Japonesa. Na edição de 1991, um novo posfácio é publicado.

A visão americana média e de praticamente todo o Ocidente sobre o Japão do imediato pós-guerra até nossos dias é que o imperador japonês e sua força armada, numa desenfreada ambição de poder, expandiram sua área de ação nos anos 20 e 30 cometendo todo tipo de atrocidades, especialmente contra o povo coreano e chinês. Esta política expansionista culminou com o ataque à base naval americana Pearl Harbor, que foi de imediato respondido pelos Estados Unidos. Com o lançamento das bombas atômicas sobre Hiroshima e Nagazaki em 1945, o Japão deu-se por vencido e as Forças de Ocupação permaneceram naquele território até 1952. Os Estados Unidos ajudaram a reconstruir a sociedade e a economia japonesas através de vários mecanismos como a transferéncia tecnológi- 
ca e a compra de seus produtos. Dessa forma, os japoneses devem favores aos americanos.

Uma outra visão alternativa a estes mesmos acontecimentos pode ser expressa por japoneses mais radicalmente nacionalistas. Para eles, o Japão tem-se desenvolvido rapidamente desde a tentativa de colonização, quando da chegada dos navios negros - Comodoro Perry, nos anos 50 do século passado. Os japoneses foram forçados a vencer os russos em 1905, e uma vez que se tomaram uma potência econômica nos anos 30 , frequientemente contida por americanos e ingleses, desencadeou-se uma resposta militar. Um punhado de militares inconseqüentes atacaram Pearl Harbor ocasionando a entrada dos Estados Unidos na guerra. O presidente Roosevelt ordenou o lançamento das bornbas atômicas sobre os japoneses e näo sobre os alemães porque os americanos são racistas. O Japão trabalhou duro e das cinzas tornou-se novamente uma potência econômica, não devendo nada para nínguém.

Movendo-se entre essas duas simplificadas visões históricas, Holstein trabalha uma gama enorme de assuntos culturais, políticos, econômicos, administrativos e de políticas governamentais, para criar um amplo quadro explicativo da sociedade japonesa contrastada com a sociedade americana. Sociedade esta que vem perdendo sua liberdade pela crescente invasão dos interesses econômicos japoneses presentes em todo o mundo.

Ressaltando que suas viagens e pesquisas para a realização do livro foram financiadas por ele próprio, discute como os japoneses gerenciam os americanos; fundamentalmente financiando-os e/ou comprando-os; e lança um desafio à sociedade americana. $O$ desafio consiste da busca de uma estratégia nacional que diminua as diferenças entre republicanos e democratas, entre conservadores e liberais, entre os amantes do Japão e os que o odelam com o explícito objetivo de alcançar um balanço nas relaçôes económicas entre os Estados Unidos e o Japão. Esta estratégia seria o "Patriotismo Econổmico".

Antes de chegar a esta proposição, Holstein analisa as principais caracteristicas da sociedade japonesa em cinco itens da primeira parte: 1. Mudança, näo mudança; 2. A difícil cultura; 3. Mulheres num mundo de homens; 4 . Batendo na parede e 5.0 prisma japonês. Chama atenção também para os desenvolvimentos e superficialidades de análises da sociedade japonesa quando esclarece "... que a razño para tanta confusão é que americanos e outros ocidentais tendem a se apoiat em simbolos que têm ecoado em suas próprias culturas e interprétá-los num contexto que tem pouco sentido ao que os próprios japoneses percebem estar acontecendo".

Após acurada análise das características da sociedade japonesa, $o$ autor procura desvendar o "escândalo" que envolveu o governo japonês em disputas políticas e ca" sos de corrupção ao longo da década de 80 eclodindo no seu final, o que ficou mundialmente conhecido como o caso Recruit. Embora o escãndalo tenha envolvido vários ministérios, Holstein descreve o reinado das telecomunicaçöes como peça central do caso. Toda a trama envolvendo principalmente a NTT - Nippon Telegraph and Telephone e a Empresa Recruit é reconstituída nos seis itens da segunda parte: 6.0 reinado; 7 . Os desafiantes; 8.0 ataque; 9 . Tropeçando numa pedra pequena; 10. Os negócios de Uno e 11. Socialistas: um efểmero chamariz.

Discutindo a realidade japonesa e seus caminhos furturos nos aspectos mais estritamente ligados ao mundo dos negócios e da política, uma vez que os psicológicos, sociológicos e culturais foram analisados na primeira parte, Holstein elabora a terceira parte subdividida em: 12. A rolagem do sistema político; 13. Tendência nacionalista?; 14. Decolagem econômica; 15 . Tornando-se global: valores; 16. Tomando-se global: exportando os Keiretsu; 17. Tem o investimento japonês criado igualdade? e 18. Gerenciando os americanos.

Todos esses itens são descritos possuindo como idéia central o poder do capital uma vez que "... se a força e de" terminaçĩo da economia americana säo vistas como perdendo vigor, então os Estados Unidos perdem credibilitade. Esta é a maneira que o jogo do poder é jogado. Os fracos e falidos nâo recebem solidariedade no Japäo, mas, sim, desprezo. Consequientemente, o futuro das atitudes e políticas japonesas está 1 gado com sua força econônica. Se nós temos o poder, nós estamos certos".

Uma vez apresentado os pontos fortes da economia e sociedade japonesas, seu atual estágio e intençôes futuras, o mesmo é feito com a sociedade americana quando o autor discute a resposta americana através de: 19. Repensando o Japão; 20. Patriotismo económico; 21. Política industrial congestionada; 22 . Investimento: absorção dos benefícios, 23. Um futuro pacifico. Neste último item, Holstein discute a formação de um novo capitalismo, de um capitalismo de tipo asiático. No início do item, destaca uma opintão de 1905 de Theodore Roosevelt sobre o Japão quando afirma "...Ela é tuma grande e ciwilizada naçäo; no entanto, sua civilizaçâ é em muitos e im. portantes aspectos diferente da nossa. Existem algumas coisas que ela pode nos ensinar e algumas coisas que ela pode aprender de nôs". Pela discussão do capítulo e de todo o conteúdo do livro de Holstein, a opinião do presidente americano, após quase um século, ainda é verdadeira.

Aos que acreditam que a opinião de Roosevelt é verdadeira, O loga de Poder Japonếs é de leitura indispensável. Os que compartilham da primeira visão sobre a sociedade japonesa, simplificadamente exposta no início desta resenha, também devem ler todo o livro para entender o que este jogo significa aos americanos, e os que compartilham da segunda visão devem lê-lo para compreender o que este jogo significa para os japoneses. Dessa maneira, o livro de Holstein deve ser lido por todos que direta ou indiretamente fazem parte do jogo. 